\title{
Fases de Realização e Tipos de Projectos de InStalações Eléctricas
}

\section{INTRODUÇão}

A realização do projecto eléctrico de uma instalação requer, além do domínio técnico dos assuntos particulares que a esta digam respeito, sistematização na sua abordagem e programação, necessária tanto no faseamento da sua concepção como na elaboração processual dos seus documentos.

Neste sentido a publicação da portaria no 701-H/2008, de 29 de Julho, através do seu anexo 1 - Instruções para a Elaboração de Projectos de Obras - representa um salto qualitativo significativo no processo de realização do projecto, visando uma concepção de mais elevada qualidade do mesmo, ao definir a metodologia a seguir na sua elaboração, com discriminação das suas fases, seus conteúdos e objectivos.

Embora a portaria se destine expressamente a projectos de obras públicas e uma vez que a caracterização das obras particulares se rege, de um modo geral, pelas regras das obras públicas, a transposição dos seus princípios para aquele tipo de obras representa uma mais-valia significativa para o projectista e para a consequente melhoria do projecto electrotécnico.

Este artigo faz uma ligeira incursão nos aspectos das Instruções para a Elaboração e revêem-se alguns princípios formais da estruturação do projecto de licenciamento.

\section{LEgISLAÇ̃̃o APLICÁVEL}

- Decreto-Lei no 26 852, de 30 de Julho de 1936 - Aprova o Regulamento de Licenças para Instalações Eléctricas

- Portaria no 401/76, de 6 de Julho - Estabelece as normas a que deverão obedecer os projectos destinados a instruírem os pedidos de licença de instalações eléctricas de serviço público

- Decreto-Lei no 446/76, de 5 de Junho - Dá nova redacção a alguns artigos do Regulamento de Licenças para Instalações Eléctricas, aprovado pelo Decreto-Lei n.응 26852 de 30 de Julho de 1936
- Decreto-Lei no 517/80, de 31 de Outubro - Estabelece normas a observar na elaboração dos projectos das instalações eléctricas de serviço particular

- Decreto Regulamentar no 31/83, de 18 de Abril - Aprova - Estatuto do Técnico Responsável por Instalações Eléctricas de Serviço Particular

- Portaria no 344/89, de 13 de Maio - Altera os artigos 19. e 20. do Decreto-Lei n.o 26852 de 30 de Julho de 1936. Revoga a Portaria n. $24 / 80$ de 9 de Janeiro

- Decreto-Lei no 272/92, de 3 de Dezembro - Estabelece normas relativas às associações inspectoras de instalações eléctricas

- Decreto-Lei no 315/95, de 28 de Novembro - Regula a instalação e o funcionamento dos recintos de espectáculos e divertimentos públicos e estabelece o regime jurídico dos espectáculos de natureza artística

- Decreto-Lei no 59/99, de 2 Março - Estabelece o regime do contrato administrativo de empreitada de obras públicas.

- Decreto-Lei no 555/99, de 16 de Dezembro (com as alterações subsequentes)- Estabelece o regime jurídico da urbanização e da edificação

- Portaria no 454/2001, de 5 de Maio - Aprova o novo contrato-tipo de concessão de distribuição de energia eléctrica em baixa tensão

- Portaria no 1110/2001, de 19 de Setembro - Determina quais os elementos que devem instruir os pedidos de informação prévia, de licenciamento e de autorização referentes a todos os tipos de operações urbanísticas

- Decreto-Lei n.o 5/2004, de 6 de Janeiro - Aprova a orgânica das direç̧ões regionais da economia

- Portaria no 193/2005, de 17 de Fevereiro - Actualiza a relação das disposições legais e regulamentares a observar pelos técnicos responsáveis dos projectos de obras e a sua execução

Decreto-Lei no 229/2006, de 24 de Novembro - Altera o Decreto Regulamentar n. 31/83 de 18 de Abril, que aprova o Estatuto do Técnico Responsável por Instalações Eléctricas de Serviço Particular, e derroga 
parcialmente o disposto na alínea e) do n.o 3 do artigo 3. o do Decreto-Lei n.o 5/2004, de 6 de Janeiro

- Decreto-Lei no 101/2007, de 2 de Abril - Simplifica o licenciamento de instalações eléctricas, quer de serviço público quer de serviço particular, alterando os Decretos-Lei n.os 26 852, de 30 de Julho de 1936, $517 / 80$, de 31 de Outubro, e 272/92, de 3 de Dezembro

- Lei no 60/2007, de 4 de Setembro - Procede à sexta alteração ao Decreto -Lei n.o 555/99, de 16 de Dezembro, que estabelece o regime jurídico da urbanização e edificação

- Decreto-Lei no 18/2008, de 29 de Janeiro - Aprova o Código dos Contratos Públicos, que estabelece a disciplina aplicável à contratação pública e o regime substantivo dos contratos públicos que revistam a natureza de contrato administrativo

- Portaria no 232/2008, de 11 de Março - Determina quais os elementos que devem instruir os pedidos de informação prévia, de licenciamento e de autorização referentes a todos os tipos de operações urbanísticas, e revoga a Portaria n. $1110 / 2001$ de 19 de Setembro

- Portaria no 701-H/2008, de 29 de Julho - Aprova o conteúdo obrigatório do programa e do projecto de execução, bem como os procedimentos e normas a adoptar na elaboração e faseamento de projectos de obras públicas, designados «Instruções para a elaboração de projectos de obras», e a classificação de obras por categorias

\section{DEFINIÇõES}

- Anteprojecto ou Projecto Base - o documento a elaborar pelo Projectista, correspondente ao desenvolvimento do Estudo prévio aprovado pelo Dono da Obra, destinado a estabelecer, em definitivo, as bases a que deve obedecer a continuação do estudo sob a forma de Projecto de execução.

(Ao Projecto Base também se dá o nome de Projecto de Licenciamento, pois nesta fase o projectista prepara as peças escritas e as peças desenhadas para entregar o projecto para aprovação).
- Dono da Obra - pessoa colectiva ou individual que promove o projecto ou obra

Os donos de obra podem classificar-se em dois tipos: donos de obra pública e de obra particular

Os donos de obra pública são as entidades que se encontram sujeitas ao Regime Jurídico de Obras Públicas, conforme define o art.o 3.o do Decreto-Lei n.o 59/99, de 2 de Março. Alguns donos de obra pública encontram-se sujeitos ao Regime de Licenciamento Urbano (DecretoLei n. 555/99 de 16 de Dezembro)

Os donos de obra particular encontram-se sujeitos, nas operações de licenciamento de urbanizações e de edificações, às disposições do Decreto-Lei n.o 555/99 de 16 de Dezembro

- Estudo prévio - o documento elaborado pelo Projectista, depois da aprovação do programa base, visando a opção pela solução que melhor se ajuste ao programa, essencialmente no que respeita à concepção geral da obra

- Peças do projecto - os documentos, escritos ou desenhados que caracterizam as diferentes partes de um projecto

- Programa base - o documento elaborado pelo Projectista a partir do programa preliminar resultando da particularização deste, visando a verificação da viabilidade da obra e do estudo de soluções alternativas, o qual, depois de aprovado pelo Dono da Obra, serve de base ao desenvolvimento das fases ulteriores do projecto

- Programa preliminar - o documento fornecido pelo Dono da Obra ao Projectista para definição dos objectivos, características orgânicas e funcionais e condicionamentos financeiros da obra, bem como dos respectivos custos e prazos de execução a observar

- Projecto - o conjunto de documentos escritos e desenhados que definem e caracterizam a concepção funcional, estética e construtiva de uma obra, compreendendo, designadamente, o projecto de arquitectura e projectos de engenharia.

- Projecto de execução - o documento elaborado pelo Projectista, a partir do estudo prévio ou do anteprojecto aprovado pelo Dono da Obra, destinado a facultar todos 
os elementos necessários à definição rigorosa dos trabalhos a executar

Telas finais - o conjunto de desenhos finais do projecto, integrando as rectificações e alterações introduzidas no decurso da obra e que traduzem o que foi efectivamente construído

\section{Fases do Projecto}

A realização do Projecto deve seguir um cronograma específico, caracterizado pela definição de etapas sucessivas em número dependente da importância e complexidade da obra, de pormenorização crescente e tendente à fixação definitiva das soluções, culminando na elaboração do Projecto de Licenciamento e no de Execução.

Estas fases podem ser enumeradas do modo seguinte de acordo com a portaria citada:

- Programa Base

- $\quad$ Estudo Prévio

- Anteprojecto (Projecto Base ou Projecto de Licenciamento)

- Projecto de Execução

Estas seguem-se cronologicamente às especificações fornecidas pelo Dono da Obra ao Projectista e traduzidas no Programa Preliminar.

Como características que estas fases devem conter, incluemse as seguintes:

\section{- Programa preliminar}

O Programa preliminar contém, além de elementos específicos constantes da legislação e regulamentação aplicável, os seguintes elementos, podendo alguns destes ser dispensados consoante a obra a projectar:

a) Objectivos da obra;

b) Características gerais da obra;

c) Dados sobre a localização do empreendimento;

d) Elementos topográficos, cartográficos e geotécnicos, levantamento das construções existentes e das redes de infra-estruturas locais, coberto vegetal, características ambientais e outros eventualmente disponíveis, a escalas convenientes; e) Dados básicos relativos às exigências de comportamento, funcionamento, exploração e conservação da obra, tendo em atenção as disposições regulamentares;

f) Estimativa de custo e respectivo limite dos desvios e eventualmente, indicações relativas ao financiamento do empreendimento;

g) Indicação geral dos prazos para a elaboração do projecto e para a execução da obra.

\section{- Programa Base}

O Programa base é apresentado de forma a proporcionar ao Dono da Obra a compreensão clara das soluções propostas pelo Projectista, com base nas indicações expressas no programa preliminar, incluindo:

a) Esquema da obra e programação das diversas operações a realizar, quando aplicável;

b) Definição dos critérios gerais de dimensionamento das diferentes partes constitutivas da obra;

c) Peças escritas e desenhadas e outros elementos informativos necessários para o perfeito esclarecimento do Programa Base, no todo ou em qualquer das suas partes, incluindo as que porventura se justifiquem para definir as alternativas de solução propostas pelo Projectista e avaliar a sua viabilidade, em função das condições de espaço, técnicas, de custos e de prazos;

d) Estimativa geral do custo da obra, tomando em conta os encargos mais significativos com a sua realização e análise comparativa dos custos de manutenção e consumos da obra nas soluções propostas;

e) Informação sobre a necessidade de obtenção de elementos topográficos, geológicos, geotécnicos, hidrológicos, climáticos, características da componente acústica do ambiente, redes de infra-estruturas ou de qualquer outra natureza que interessem à elaboração do projecto, bem como sobre a realização de estudos em modelos, ensaios, maquetes, trabalhos de investigação e quaisquer outras actividades ou formalidades que podem ser exigidas, quer para a elaboração do projecto, quer para a execução da obra. 
- Estudo Prévio

1- O Estudo prévio desenvolve as soluções aprovadas no Programa Base, sendo constituído por peças escritas e desenhadas e por outros elementos informativos, de modo a possibilitar ao Dono da Obra a fácil apreciação das soluções propostas pelo Projectista e o seu confronto com os elementos constantes naquele.

2- Se outras condições não forem fixadas no contrato, o Estudo prévio contém, para cada uma das soluções alternativas apresentadas à aprovação do Dono da Obra, e sem prejuízo dos elementos constantes da regulamentação aplicável, os elementos seguintes:

a) Memória descritiva e justificativa, incluindo capítulos respeitantes a cada um dos objectivos relevantes do estudo prévio;

b) Elementos gráficos elucidativos sob a forma de plantas, alçados, cortes, perfis, esquemas de princípio e outros elementos, em escala apropriada;

c) Dimensionamento aproximado e características principais dos elementos fundamentais da obra;

d) Estimativa do custo da obra e do seu prazo de execução.

- Anteprojecto ou Projecto base (Projecto para Licenciamento)

1- O Anteprojecto, ou Projecto base, desenvolve a solução do Estudo prévio aprovado, sendo constituído por peças escritas e desenhadas e outros elementos de natureza informativa que permitam a conveniente definição e dimensionamento da obra, bem como o esclarecimento do modo da sua execução.

2- Se outras condições não forem fixadas no contrato, o anteprojecto deve conter, para além dos elementos constantes da regulamentação aplicável os seguintes:

a) Memórias descritivas e justificativas da solução adoptada, incluindo capítulos especialmente destinados a cada um dos objectivos especificados para o anteprojecto, onde figuram designadamente descrições da solução orgânica, funcional e estética da obra, dos sistemas e dos processos de construção previstos para a sua execução e das características técnicas e funcionais dos materiais, elementos de construção, sistemas e equipamentos;

b) Avaliação das quantidades de trabalho a realizar por grandes itens e respectivos mapas;

c) Estimativa de custo actualizada;

d) Peças desenhadas a escalas convenientes e outros elementos gráficos que explicitem a localização da obra, a planimetria e a altimetria das suas diferentes partes componentes e o seu dimensionamento bem como os esquemas de princípio detalhados para cada uma das Instalações Técnicas, garantindo a sua compatibilidade;

e) Identificação de locais técnicos, centrais interiores e exteriores, bem como mapa de espaços técnicos verticais e horizontais para instalação de equipamentos terminais e redes.

f) Os elementos de estudo que serviram de base às opções tomadas, de preferência constituindo anexos ou volumes individualizados identificados nas memórias;

g) Programa geral dos trabalhos.

\section{- Projecto de execução}

1- O Projecto de execução desenvolve o Projecto base aprovado, sendo constituído por um conjunto coordenado das informações escritas e desenhadas de fácil e inequívoca interpretação por parte das entidades intervenientes na execução da obra, obedecendo ao disposto na legislação e regulamentação aplicável.

2- Se outras condições não forem fixadas no contrato, o Projecto de execução inclui, além de outros elementos constantes de regulamentação aplicável, as seguintes peças:

a) Memória descritiva e justificativa, incluindo a disposição e descrição geral da obra, evidenciando quando aplicável a justificação da implantação da obra e da sua integração nos condicionamentos locais existentes ou planeados; descrição genérica da solução adoptada com vista à satisfação das disposições legais e regulamentares em vigor; indicação das características dos materiais, dos 
elementos da construção, dos sistemas, equipamentos e redes associadas às Instalações Técnicas;

b) Cálculos relativos às diferentes partes da obra apresentados de modo a definirem, pelo menos, os elementos referidos na regulamentação aplicável a cada tipo de obra e a justificarem as soluções adoptadas;

c) Medições e mapas de quantidade de trabalhos, dando a indicação da natureza e da quantidade dos trabalhos necessários para a execução da obra;

d) Orçamento baseado nas quantidades e qualidades de trabalho constantes das medições;

e) Peças desenhadas de acordo com o estabelecido para cada tipo de obra na regulamentação aplicável, devendo conter as indicações numéricas indispensáveis e a representação de todos os pormenores necessários à perfeita compreensão, implantação e execução da obra;

f) Condições técnicas, gerais e especiais, do caderno de encargos.

Caso a instalação não careça de projecto, do Estudo Prévio passar-se-á directamente para o Projecto de Execução.

O anexo I do Decreto-Lei no 517/80, de 31 de Outubro, na redacção actual do Decreto-Lei no 101/2007, de 2 de Abril, lista as instalações eléctricas que carecem de projecto:

1) Instalações eléctricas de serviço particular do tipo A;

2) Instalações eléctricas de serviço particular do tipo B;

3) Instalações eléctricas de serviço particular do tipo C situadas em recintos públicos ou privados destinados a espectáculos ou outras diversões, incluindo-se, nomeadamente, teatros, cinemas, praças de touros, casinos, circos, clubes, discotecas, piscinas públicas, associações recreativas ou desportivas, campos de desporto, casas de jogo, autódromos e outros recintos de diversão;

4) Instalações eléctricas estabelecidas em locais sujeitos a risco de explosão;

5) Instalações de parques de campismo e portos de recreio (marinas);
6) Instalações eléctricas de serviço particular do tipo C cuja potência a alimentar pela rede seja superior a 50 kVA;

7) Redes particulares de distribuição de energia eléctrica em baixa tensão e respectivas instalações de iluminação exterior.

A pormenorização e alcance de cada fase variará de acordo com as características particulares associadas ao tipo de empreendimento a projectar. Assim, teremos sucessivamente:

- Instalações, Equipamentos e Sistemas em Edifícios

- Instalações, Equipamentos e Sistemas de Comunicação em Edifícios

- Instalações, Equipamentos e Sistemas de Aquecimento, ventilação e ar condicionado (AVAC)

- Instalações, Equipamentos e Sistemas de transporte de pessoas e cargas

- Sistemas de Segurança Integrada

- Produção, transformação, transporte e distribuição de Energia Eléctrica

- Redes de comunicações

Para cada tipo de instalação enunciada se procede à pormenorização dos objectivos a alcançar em cada uma das fases do projecto cuja satisfação será levada à consideração do Dono da Obra para aprovação.

Exemplificando com a primeira das obras consideradas, teremos, como elementos especiais das diversas fases, os seguintes:

\section{- Programa Preliminar}

a) Identificação de aspectos específicos do edifício ou zonas do edifício, em termos de energia eléctrica, ambiente, utilização, segurança e outros e ligações a redes ou sistemas exteriores.

b) Condicionamentos à localização dos equipamentos e das instalações necessárias ao seu funcionamento.

c) Identificação dos níveis de qualidade, disponibilidade, redundância e autonomia pretendidos.

d) Condicionamentos a nível de manutenção, exploração e expansão. 


\section{- Programa Base}

a) Identificação das diferentes instalações e equipamentos a considerar e suas configurações gerais justificadas a partir dos condicionamentos e imposições do Programa Preliminar

b) Bases de dimensionamento consideradas para as diferentes instalações e equipamentos.

c) Discriminação e justificação das necessidades em termos de energia eléctrica, segurança e outras.

d) Interligações com outras especialidades e respectivas condições ou exigências.

\section{- Estudo Prévio}

a) Representação gráfica geral das instalações e equipamentos em concordância com o desenvolvimento das outras especialidades e com a definição das condições regulamentares de segurança, sob a forma de plantas e outros elementos, a escala apropriada.

b) Esquemas de princípio necessários à definição esquemática da concepção dos sistemas e redes que integram as instalações e equipamentos e da sua interligação espacial e funcional.

c) Caracterização genérica das instalações e equipamentos principais.

d) Pré-dimensionamento dos equipamentos e das redes principais das instalações.

e) Condições de ligação às redes de energia eléctrica (produção, consumo) e outras, de funcionamento e utilização das instalações e equipamentos e da sua eventual expansão.

\section{- Anteprojecto (Projecto Base, Projecto de} Licenciamento)

a) Plantas, em escalas apropriadas, onde se indiquem os traçados das redes principais das diversas instalações, com indicação da localização aproximada dos equipamentos.

b) Cortes, esquemas e diagramas, sempre que isso seja necessário à boa compreensão da solução proposta.

c) Esquemas de princípio das instalações e da sua interligação espacial e funcional. d) Caracterização das instalações e equipamentos principais.

e) Dimensionamentos dos equipamentos e redes principais das instalações.

f) Enumeração dos principais artigos que constituem o mapa de quantidades de trabalho, dividido nos principais capítulos constituintes das instalações e equipamentos, de forma a permitir a elaboração da estimativa do custo preliminar da obra.

g) Justificação dos níveis de conforto luminotécnico, de segurança e outros, bem como de produção e consumo de energia eléctrica que suportem a solução proposta;

h) Verificação do cumprimento das regulamentações técnicas aplicáveis.

\section{- Projecto de Execução}

a) Memória descritiva e justificativa, incluindo a análise prospectiva de desempenhos, descrevendo e justificando as soluções projectadas, tendo em atenção o Anteprojecto aprovado e as disposições legais em vigor.

b) Condições técnicas, gerais e especiais, especificando as condições de execução ou montagem e as características técnicas das instalações e equipamentos previstos.

c) Planta geral dos locais servidos pelas instalações $e$ equipamentos, em escala apropriada, quando não definida em regulamento aplicável, contendo os elementos de referência e de orientação necessários à fácil localização das instalações e equipamentos.

d) Plantas em escala apropriada, quando não definida em regulamento aplicável, com o traçado e constituição das redes e localização dos equipamentos, com a indicação dos elementos indispensáveis à sua conveniente apreciação.

e) Alçados e cortes dos edifícios ou partes dos edifícios, sempre que isso seja necessário à boa compreensão do projecto, a escala apropriada, quando não definida em regulamento aplicável.

f) Pormenores necessários à definição detalhada e boa execução das instalações e equipamentos projectados, a escalas apropriadas quando não definidas em regulamento aplicável. 
g) Esquemas de princípio das instalações e da sua interligação espacial e funcional, quando necessárias à sua perfeita compreensão.

h) Dimensionamento das instalações e dos equipamentos, incluindo os cálculos necessários para o efeito.

i) Medições e mapas de quantidade de trabalhos, divididos nos diversos capítulos constituintes da obra.

j) Orçamento de projecto da obra.

Além das fases enunciadas, há uma outra não menos importante que é a Assistência Técnica, prestada e solicitada pelo Projectista ao Dono da Obra. Esta é requerida antes e durante a execução da obra:

1- Na fase do procedimento de formação do contrato, e até à adjudicação da obra, a Assistência técnica do Projectista ao Dono da Obra compreende as actividades seguintes:

a) Esclarecimento de dúvidas relativas ao projecto durante a preparação do processo do concurso para adjudicação da empreitada ou fornecimento;

b) Prestação de informações e esclarecimentos solicitados por candidatos a concorrentes, sob a forma escrita e exclusivamente por intermédio do Dono da Obra, sobre problemas relativos à interpretação das peças escritas e desenhadas do projecto;

c) Prestação do apoio ao Dono da Obra na apreciação e comparação das condições da qualidade das soluções técnicas das propostas de molde a permitir a sua correcta ponderação por aquele, incluindo a apreciação de compatibilidade com o projecto de execução, constante do caderno de encargos, de variantes ou alterações que sejam apresentadas;

2- Durante a execução da obra, a assistência técnica compreende:

a) Esclarecimento de dúvidas de interpretação de informações complementares relativas a ambiguidades ou omissões do projecto, bem como elaboração das peças de alteração do projecto necessárias à respectiva correcção e à integral e correcta caracterização dos trabalhos a executar no âmbito da referida correcção;

b) Apreciação de documentos de ordem técnica apresentados pelo empreiteiro ou Dono da Obra, incluindo, quando apropriado, a sua compatibilidade com o projecto;

c) Proceder, concluída a execução da obra, à elaboração das Telas Finais a ela respeitantes, verificando a conformidade das mesmas com o projecto de execução e das eventuais alterações nele introduzidas, de acordo com as informações fornecidas pelo Dono da Obra.

\section{Elaboração do Projecto de Licenciamento}

O projecto de licenciamento é um documento técnico destinado a instruir um pedido de licença de estabelecimento de uma instalação eléctrica, por ex. uma linha aérea de alta tensão com mais de 1000 m de extensão, ou a fazer parte, na qualidade de projecto de engenharia de especialidade, de um projecto de arquitectura de uma obra que careça de licença municipal de construção, como por ex um prédio de habitações e escritórios.

O projecto pode ainda ser de obra que não careça de licença municipal $^{1}$ ou de estabelecimento ${ }^{2}$. De todos os modos é um documento apresentado a aprovação.

Daí a sua constituição ser objecto de legislação específica pois tratando-se de um documento a ser sujeito a apreciação técnica e à análise da observância do disposto nos Regulamentos de Segurança aplicáveis a sua forma necessita ser adequada à transmissão da informação requerida e organizada de tal maneira que a consulta seja fácil, elucidativa, tanto quanto possível exaustiva e inequívoca.

A estrutura básica do projecto é composta de uma parte preliminar e de um corpo, constituído este por uma parte textual e uma outra de desenhos.

\footnotetext{
${ }^{1}$ As obras que não carecem de concessão de licença administrativa, passada pela Câmara Municipal respectiva, são as referidas no DL no 555 , Regime Jurídico da Urbanização e Edificação, art. 6ㅇ, com as alterações introduzidas pelo DL n.o 177/2001, de 4/06 e Lei n.ㅇ 60/2007, de 04/09

${ }^{2}$ As instalações eléctricas que não carecem de licença de estabelecimento são as referidas nos arts. 9o, 27ㅇ e 28 do DL no 26852 , de 30 de Julho de 1936, com as alterações introduzidas pelos DL no 446/76, de 05/06 e DL no 101/2007, de 02/04
} 
À parte textual dá-se o nome de Peças Escritas e ao conjunto de desenhos, plantas, alçados, cortes, perfis, diagramas, outras representações gráficas o de Peças Desenhadas.

\section{- Corpo do Projecto}

Como partes em que o projecto se divide podemos considerar as seguintes:

- Memória descritiva e justificativa

- Caderno de encargos

- Medições e orçamento

- Peças desenhadas

\section{- Memória Descritiva e Justificativa}

A memória descritiva e justificativa do projecto deve conter todos os elementos e esclarecimentos necessários para darem uma ideia perfeita da natureza, importância, função e características das instalações e do equipamento.

\section{- Caderno de Encargos (CE)}

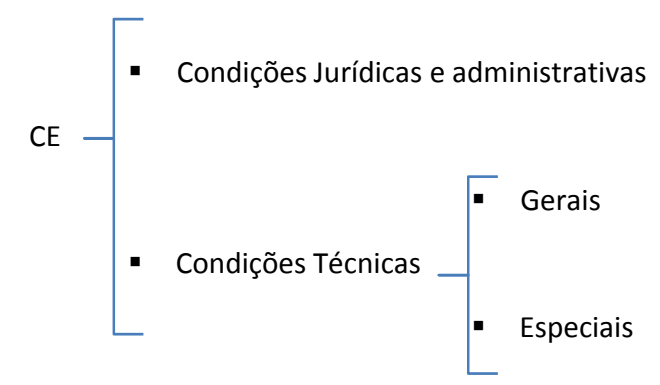

Condições Jurídicas e Administrativas - Condições que a entidade compradora, o Adjudicante, formaliza à entidade fornecedora, o Adjudicatário, relativa a aspectos tais como cauções, garantias, obrigações, prazos, facturação e condições de pagamento, seguros, cessões, incumprimentos e penalidades.

\section{Condições Técnicas:}

Gerais - Referência ao objecto e extensão da empreitada, contemplando o fornecimento e montagem de todos os materiais e equipamentos eléctricos, e às condições que devem reger as tarefas a realizar no que diz respeito à observância dos regulamentos em vigor e às regras inerentes à boa técnica de execução dos diversos trabalhos.

Especiais - Definição de modo exaustivo e tão completo quanto possível de todos os componentes da instalação e dos trabalhos relativos à sua implantação.

\section{- Medições e Orçamento}

Determinação, com o rigor possível, das quantidades dos materiais a empregar e dos trabalhos a realizar e atribuição dos valores correspondentes à instalação de cada unidade de material e execução de cada espécie de trabalho.

\section{- Peças Desenhadas}

Conjunto de esquemas eléctricos e outros desenhos relativos à obra em questão feitos a escalas convenientes e permitindo a perfeita compreensão dos pormenores, estabelecimento e localização da instalação.

No entanto, a forma final a dar ao Projecto de Licenciamento não necessita ter todos estes componentes, pelo menos ao seu nível mais pormenorizado.

\section{CONCLUSÕES}

A existência de um projecto, deve conferir, por si só, uma garantia de qualidade, segurança e funcionalidade das instalações, assim como a diminuição dos custos de execução e exploração das mesmas, uma vez que o técnico tem de ter a consciência de que o exercício da sua profissão o obriga não só a cumprir a lei, o preceituado nos Regulamentos de Segurança, como também, dominar o estado da arte no âmbito das Instalações Eléctricas.

O projecto é uma actividade complexa e exigente pela diversidade das suas áreas e número de intervenientes no mesmo.

As Instruções para a Elaboração de Projectos de Obras, anexas à portaria no $701-\mathrm{H} / 2008$, de 29 de Julho, ao sistematizarem a sua abordagem introduziram no processo um mecanismo de regulação que constitui uma mais-valia sensível para a actividade de projectista. 